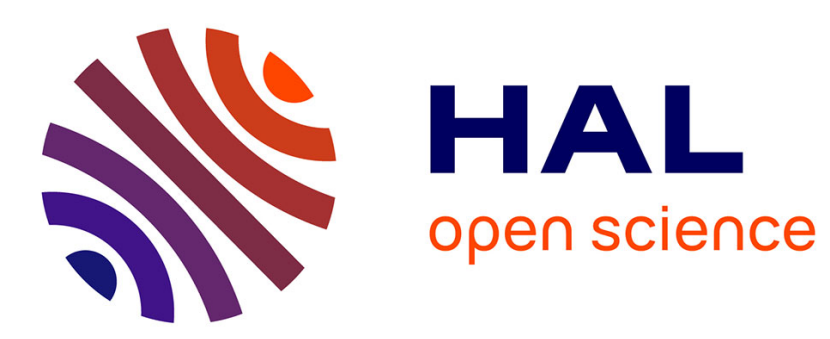

\title{
The We and the I: The Logic of Voluntary Associations
}

Ekaterina Melnik, Jean-Benoît Zimmermann

\section{To cite this version:}

Ekaterina Melnik, Jean-Benoit Zimmermann. The We and the I: The Logic of Voluntary Associations.

2015. halshs-01109609

\section{HAL Id: halshs-01109609 \\ https://shs.hal.science/halshs-01109609}

Preprint submitted on 26 Jan 2015

HAL is a multi-disciplinary open access archive for the deposit and dissemination of scientific research documents, whether they are published or not. The documents may come from teaching and research institutions in France or abroad, or from public or private research centers.
L'archive ouverte pluridisciplinaire HAL, est destinée au dépôt et à la diffusion de documents scientifiques de niveau recherche, publiés ou non, émanant des établissements d'enseignement et de recherche français ou étrangers, des laboratoires publics ou privés. 


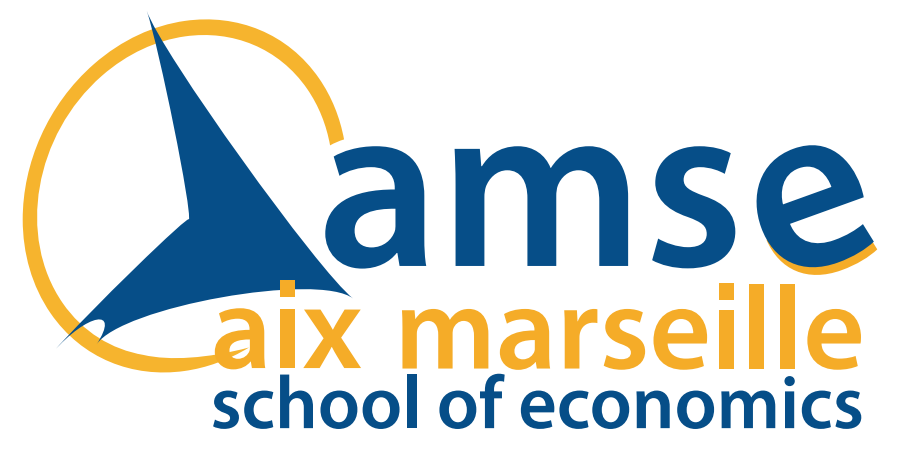

\section{Working Papers / Documents de travail}

The We and the I: The Logic of Voluntary Associations

Ekaterina Melnik Jean-Benoît Zimmermann 


\title{
The We and the I: \\ The Logic of Voluntary Associations
}

\author{
Ekaterina Melnik \\ CEE and LEST / Aix-Marseille University and CNRS \\ and Jean-Benoît Zimmermann * \\ GREQAM / Aix-Marseille University (Aix-Marseille School of Economics), CNRS and EHESS
}

January 2015

\begin{abstract}
:
This paper sheds new light on the economic logic of voluntary associations and the relationship between individual contribution and collective action. The aims are twofold.

Firstly, we seek to explain how "team reasoning" (Bacharach et al. 2006) can deeply change the functioning of voluntary associations (which are considered to produce a public good) when some or all of the individual members group together to make collective decisions about their involvement or contribution, rather than deciding separately. Secondly, we seek to better understand the effects of heterogeneity of resources on individual involvement, in terms of both the budget constraints of individual members and their capacity to contribute differentiated non-monetary contributions to the association, in relation to the diversity of their personal abilities and preferences about the characteristics of the good produced.

To this end, we use a model of voluntary association collectively producing a public good, where monetary contributions (compulsory fees plus voluntary donations) is combined with volunteering. We analyze the conditions for an association to offer profitable conditions to its members and the consequences that can be drawn in terms of its existence and size. We show that, at equilibrium, the level of voluntary contributions is ceteris paribus higher when individuals make their decisions on the basis of team-reasoning rather than individually. We analyze the role played by heterogeneity of incomes in the formation of teams within associations.

We then introduce the concept of subjective quality into the basic model. The originality of the model is that we assume the public good to be characterized by at least two main components: quantity and quality. The quantity is considered here as a purely public component, insofar as all the members benefit equally from it. However, the quality of the public good is assumed to be a mixed (public and private) component. The agents can enjoy part of it in the same way, but there may be certain characteristics of quality that are difficult or impossible to measure objectively. Quality is always somewhat subjective, to the extent that perfect correspondence with the preferences of heterogeneous agents is unlikely to occur. In our model, the agents can contribute money and/or time and effort. The latter, which we call volunteering, allows them to influence the quality of the good (or service) provided according to their own preferences.
\end{abstract}

Keywords: Voluntary associations, public good, contribution, voluteering, team reasonning, collective action

JEL: C71, D71, H4, L3

Corresponding author - jean-benoit.zimmermann@univ-amu.fr 


\section{Introduction}

In his seminal "Logic of Collective Action", Olson (1971) stressed the role of groups in providing public goods. He pointed out that, apart for small groups or those with coercive rules, "rational, self-interested individuals will not act to achieve their common or group interests". Thus, a key issue of most public good production games is the social dilemma in which rational individuals choose to free-ride. Yet, the net outcome of their action is lower than it would be if they chose to contribute. As a consequence of free-riding, the provision of public goods characterized by decreasing returns may partly or completely fail.

In the real world, however, the picture is more optimistic, since many public goods are collectively produced and real individuals appear to be less inclined to free-riding than pure "rational" agents would be.

Voluntary associations are the archetype of groups where individuals cooperate towards a common goal (Rose, 1965, Laville and Sainsaulieu 1997). In the USA, voluntary associations rely heavily on voluntary contributions of time and money from individuals. According to Indiana University, $88 \%$ of American households donated to charities in 2012. In that year, individuals donated more than $\$ 228$ billion, while corporations and foundations gave about $\$ 18$ and $\$ 45$ billion respectively. ${ }^{1}$ In 2011, according to the Federal Agency for Service and Volunteering, 64.3 million Americans $(26.8 \%)$ volunteered about 7.9 billion hours in formal organizations. In monetary value, volunteering in formal organizations is estimated to be worth about $\$ 171$ billion. In this sense, research on the voluntary sector contributes to developing new models of institutional behavior and a richer conception of the individual utility function (Rose-Ackerman, 1996).

The aim of this paper is to provide an analytical framework for better understanding the internal economic mechanisms of the formation and functioning of voluntary associations. Why and how do they form? Through what mechanisms do rational individuals succeed in cooperating?

Empirical and experimental studies have stressed social and cultural factors, altruism and "warm glow" or merely the preference for cooperation, as important determinants of pro-social cooperative behavior (Andreoni, 1995, Crumpler and Grossman, 2008, Andreoni and Payne, 2011, Guala et al., 2013). In line with this literature, we consider in this paper that even while taking decisions individually, individuals remain social beings. We define the social dimension of an individual as the characteristics related to his or her feeling of belonging to a group. This feeling contributes to the individual's decision process. We therefore consider that individuals can behave as members of a group, i.e., be team-reasoning, acting under a "common knowledge of solidarity" (Bacharach, 1999; Bacharach et al. 2006; Guala et al., 2013).

In this paper, we develop a model of voluntary association formed by individuals for the provision of a common good. At a first step, we consider a set of agents who benefit uniformly from a quantity of a good. We show the existence of different symmetric and non-symmetric equilibria corresponding to the different modes of emergence of associations identified in the literature (Gordon and Babchuk, 1959; Rose, 1965; Laville and Sainsaulieu, 1997).

At the global N-symmetric equilibrium corresponding to the case of a "for-self" association, all the agents are equal in that they all make a fixed voluntary contribution. Voluntary contributions are crowded out by compulsory payments and by exogenous resources. At the partial K-symmetric equilibrium, where one can distinguish between two categories of agents, the "strong" and the "weak", only $K$ agents make voluntary contributions. This case corresponds to an association created "for others". Here, the effects of crowding out are also present and the level of voluntary

\footnotetext{
${ }^{1}$ Giving USA: The Annual Report on Philanthropy, a publication of Giving USA Foundation ${ }^{\mathrm{TM}}$, researched and written by the Indiana University Lilly Family School of Philanthropy.
} 
contributions falls with the size of the organization. At both the N-symmetric and the K-symmetric equilibria, the amount of voluntary contributions grows with the attractiveness of the public good. For all these types of equilibria, we show that the outcome of the collective action is more efficient when some or all individuals are "We-frame reasoning". We-frame reasoning corresponds to the decision-making process where the question "What should I do?" proceeds from the upstream question "What should we do?"

Then, by introducing a budget constraint, we show the existence of a unique partial K-symmetric equilibrium, in which the $K$ richest agents give an equal amount, while the others give the rest of their disposable income after dues. When it is assumed that the net income of the agent enters the utility function in a concave way, we find that there exists a non-symmetric equilibrium at which all the agents fix their voluntary contributions such that their net disposable incomes are equal. In the same configuration and after re-introducing the budget constraint, we show the existence of a unique equilibrium at which only the richest members form a team within the association to make additional voluntary contributions. The members of this group give an amount that makes their net incomes equal.

Finally, we introduce the possibility for agents to contribute both money and time, i.e., to volunteer. Volunteering allows them to influence the quality of the good provided according to their own preferences. In a way, quality is always somewhat subjective, insofar as perfect correspondence with the preferences of heterogeneous agents is unlikely to occur.

The paper is organized as follows. The next section provides a brief background to our study. In section 3, we present the foundations of a model of voluntary association which is considered collectively to produce a public good. The aim of the model is to better understand the functioning of voluntary organizations, in particular some recurrent issues faced by nonprofit managers: membership and volunteer recruitment and retention and the decline in volunteering (Hoye et al., 2006, Costa et al., 2006). Section 4 goes a step further by analyzing the different concepts of equilibrium in voluntary contributions according to whether individuals base their decisions on individual or team reasoning.

We then analyze the role of the heterogeneity of the members in terms of their budget constraints in section 5 and of their capabilities for non-monetary contributions in section 6 . The concept of subjective quality is introduced into the basic model.

\section{Voluntary contributions to the public good: the I for the We}

The voluntary sector is considered as an extra-governmental provider of collective consumption goods, representing an alternative for unsatisfied demand (Weisbrod, 1977, 1986, 2000.) It can be distinguished from the public and the private sectors by its methods of providing goods and services. The public provision of goods or services is financed by compulsory taxes, while on the market, individuals have to pay for their consumption. With voluntary provision, on the other hand, individuals can choose to contribute to the provision of a good or service, whether they consume it or not (Olson, 1971, Sugden, 1984), by forming voluntary associations.

Under purely economic reasoning, voluntary associations were initially considered as segregated groups that arise for the mutual benefit of their members, allowing them to share collectivelyprovided goods which could not be provided individually or which are better provided collectively. In this economic perspective, associations are considered as closed "clubs", where the "local public good" is provided exclusively to its members and the quantity is the same for everyone (Buchanan, 1965, McGuire, 1974). On the other hand, in the sociological perspective, voluntary associations were considered as serving not only the membership, but also the "public-in-contact" or "public-atlarge" (Ross, 1972, Olson, 1971). During the last two decades, the border between these 
approaches has become blurred, with the growing development of empirical studies on voluntary contributions and volunteering and with the introduction of notions of impure altruism and warm glow for giving (Andreoni, 1988, Andreoni, 1989). In this perspective, in contrast to the theory of club goods, individual contributions are not perfect substitutes, meaning that individuals can be concerned about their private provision as well as about the total amount of public goods (Bergstrom et al., 1986). This implies that public funding for instance does not completely crowd out individual contributions.

According to standard public good theory, the amount of the good provided through voluntary contributions will be sub-optimal because of free-riding. In theory, when agents are considered as pure altruists (Andreoni, 1988), i.e. when they are interested only in the total outcome of the collective action, public support leads to the complete crowding-out of voluntary contributions. However, empirical studies show that voluntary contributions are not completely crowded-out by public financial support. Moreover, in experimental studies, complete free-riding is not observed. Experimental studies allow distinguishing between different determinants of voluntary contributions. These studies show that communication and common knowledge of group affiliation tend to increase voluntary contributions (Andreoni and Petrie, 2004; Ellingsen et al, 2012; Guala et al., 2013). Other social determinants, such as certain individual characteristics (Glaeser et al., 2000), cooperative values versus individualistic values (Offermann et al., 1996), socio-economic environment (Carpenter et al., 2004, Fehr and Schmidt, 1999) also influence the provision of public goods. In other words, the social dimension matters.

Empirical studies of the voluntary sector focus largely on the factors influencing donors' behavior. These factors include state support of the provision of public goods, the total provision of public goods, the fund-raising expenditure of nonprofits and individual motivations (Andreoni and Payne, 2003; Andreoni and Payne 2012). As many empirical studies show, governmental support of the provision of public goods by the voluntary sector does not crowd-out individual contributions. In some cases, one can even observe some crowding-in. Thus, Okten and Weisbrod (2000) find no significant parameters of crowding-out in the United States, and even some crowding-in effects. In a study of international relief and development organizations, Ribar and Wilhelm (2002) show that contributions to these organizations are only weakly affected by public support, but they are positively influenced by fund-raising expenditure. In experimental studies, the crowding-out is still incomplete, although larger, probably due to the deliberate elimination of the social dimension in experiments (Andreoni 1993).

\section{A basic model: the I for the We, the We for the I}

The model presented in this section is an extension of a standard public good model. We consider a set of $N$ agents $i=1 \ldots N$ with $N>1$, who are members of an association. In what follows, $N$ denotes the size of the association. The number of members must be higher than one, by definition of an association. Each agent is endowed with an income $w_{i}$, which can be used for private consumption and for the provision of a public good $G$. All the members have to pay a compulsory amount $c$, on top of which each member can add a voluntary pecuniary contribution $d_{i}$ in order to increase production of the public good. At this stage, all the members benefit equally from the public good provided, but at a level that depends more or less on the size of the association (rivalry). Thus the utility function of each agent can be written as follows:

$$
U_{i G}=w_{i}-c-d_{i}+\frac{\theta}{N^{\gamma}}\left(N c+\sum_{j=1}^{N} d_{j}+X\right)^{\alpha},
$$




$$
0<\alpha<1, \quad 0 \leq \gamma \leq 1
$$

The variable $X$ has a double economic meaning. A positive value is interpreted as a fixed amount of monetary resources coming from exogenous origins (public grants, for instance.) A negative $X$ describes the net amount of fixed costs (fixed costs less exogenous resources).

The parameters $\alpha$ and $\theta$ describe the production technology of the public good contributing to the individual utility, in the non-linear and linear forms respectively. The parameter $\alpha$ can be interpreted in terms of more or less important decreasing returns. The parameter $\theta$ is always positive, because contributing to the good is assumed to generate a positive externality. The introduction of this parameter allows to vary the attractiveness of the good. In fact, as has been noted in some experimental studies, the attractiveness of a public good can positively influence individual voluntary contributions to it (Hichri and Kirman, 2007).

The parameter $\gamma$ denotes the publicness of the provided good by measuring its degree of rivalry (Bergstrom and Goodman, 1973; Blecha, 1987). A $\gamma$ tending towards zero corresponds to decreasing rivalry of the public good. At one extreme, $\gamma$ equal to zero describes the case of a collectiveconsumption good in the sense of Samuelson (1954). This good is completely non-rival and its consumption by one agent does not prevent others from consuming it. Think for instance of an environmental association campaigning against pollution, or an association combating a disease. In these cases, each member benefits from the totality of the results of the collective action. On the contrary, a $\gamma$ equal to 1 describes a completely rival good, equivalent to a collectively provided private good equally shared among the members. As an illustration, this type of function may correspond to the running of housing cooperatives, fairly wide-spread nonprofit organizations in countries like Canada or Switzerland.

\section{The Question of Overcrowding: Too Many I's?}

The existence of an association is conditioned by the returns individuals might expect in terms of improvement of their utility function $U_{\mathrm{ig}}$ when contributing to the production of a public good jointly with the other members. These are expected to be increasing at least until a certain size of the association.

Definition 1: By overcrowding we mean the situation where the individual benefit, for each member, from the public good provided diminishes as the number of members grows.

In our model, overcrowding may occur under certain conditions related to the size $\mathrm{N}$ of the association and to the parameters $\alpha$ and $\gamma$ characterizing the production and the sharing rule of the public good.

The case of $\gamma$ equal to zero implies the absence of overcrowding, insofar as it describes a pure public good (Samuelson, 1954). To understand overcrowding effects when $\gamma$ is strictly positive, we study the variations of the production function (2) with the number of members $N$.

$$
f(N)=\frac{1}{N^{\gamma}}\left(N c+\sum_{j=1}^{N} d_{j}+X\right)^{\alpha},
$$

Proposition 1: In the absence of fixed costs (namely when $X \geq 0$ ) there is no overcrowding. More precisely: 
- if $\gamma \geq \alpha$, returns to contribution decrease with the size of the association as the sharing rule cancels out the marginal gain expected from any individual contribution. No association of any size can be formed.

- if $\gamma<\alpha$, there exists a threshold $N_{1}$ beyond which any additional contribution increases individual utility. Thus, there is no overcrowding but there exists a minimal size which is necessary for association to occur.

An interesting point resulting from this proposition is that, in line with many empirical findings, exogenous resources $X$ (such as government support) do not crowd out individual contributions, as the threshold $N_{1}$ above which association may form is an increasing function of $X$. Thus, the size of association increases with an increase in exogenous resources.

Proposition 2: In the presence of fixed costs, (namely if $X<0$ ) there can exist an overcrowding when $\gamma>\alpha$. More precisely:

- if $\gamma \leq \alpha$, there exists a threshold $N_{0}$ beyond which any additional individual contributing increases individual utility;

- if $\gamma>\alpha$ an association may occur only if the population size $N \geq N_{0}$. Beyond the threshold $N_{l}$ there is overcrowding.

Proofs are presented in Appendix A. We begin by assuming symmetrical voluntary contributions. Then we study the sign of the derivative of the production function with respect to $\mathrm{N}$ in different configurations (fixed costs versus exogenous resources). To summarize, the sign of the derivatives of the production function varies as follows:

Table 1: The size of the association and overcrowding

\begin{tabular}{c|c|c|c|c}
\hline $\mathrm{N}$ & \multicolumn{2}{|c|}{$N_{0}=-\frac{X}{c^{\prime}}$} & \multicolumn{2}{c}{$N_{1}=-\frac{\gamma X}{(\gamma-\alpha) c^{\prime}}$} \\
\hline$\frac{d f}{d N}$ & Undefined & $\begin{array}{c}>0 \\
\text { Ossociation without } \\
\text { overcrowding }\end{array}$ & 0 & $\begin{array}{c}<0 \\
\text { Overcrowding }\end{array}$ \\
\hline
\end{tabular}

Note: Where $c^{\prime}=\mathrm{c}+\mathrm{d}$, with $\mathrm{d}$ the symmetrical voluntary contribution.

At this stage, propositions 1 and 2 can be summarized as in table 2 .

Table 2: Overcrowding

\begin{tabular}{|c|l|l|}
\hline Cases & $X>0$ & $X<0$ \\
\hline$\gamma<\alpha$ & No overcrowding & No overcrowding \\
\hline$\gamma>\alpha$ & $\begin{array}{l}\text { Association may } \\
\text { not occur }\end{array}$ & Overcrowding \\
\hline
\end{tabular}

We then extend the scope of the results by considering the internal dynamics of the association. 
Olson (1971) has already stressed the role of the internal structure of associations, and in particular its impact on the group's capacity to organize the provision of public goods. These internal structures can bring some formal or informal coordination to the process of providing the public good or organizing a collective action. A formal or informal team can be formed by individuals who decide to provide the public good even if they have to support the total cost, or at least a higher cost than the others. According to Olson, such teams can happen in relatively large groups. In this case, the public good may be provided even in non-structured groups, as some participants may be able to provide the public good to the entire group through a leadership commitment. More recently, Ray and Vohra (2001) for instance study cooperation in the provision of public goods by allowing agents to write binding agreements to form coalitions.

To take into account this type of internal dynamics, in a first extension, we demonstrate that the results obtained above hold when $K$ first members, founders for instance that can be also called "committed agents", each make a fixed voluntary contribution while newcomers $(i>K)$, or "involved agents", only contribute the compulsory amount $c$.

Then we allow the possibility for $i>K$ members to make a positive voluntary contribution, while letting the latter vary among the $K$ first members. We show that the general case results obtained above hold with these new extensions.

\section{For the rest of the paper we now consider $X \geq 0$ and $\gamma<\alpha$.}

\section{Symmetric Equilibria: from I-frame to We-frame}

Voluntary associations, as defined by Rose (1965), develop "when a small group of people, finding they have a certain interest (or purpose) in common, agree to meet and act together in order to try to satisfy that interest or achieve this purpose" (p. 390). In fact, as noted by Ross (1972), this definition is more appropriate to the originators or leaders in some associations rather than the whole membership, or for certain expressive associations (clubs, sports associations). This implies that team reasoning may or may not take place in such organizations, or may occur at the partial level of a subgroup of members, while the others continue to make their decisions in isolation. If some of the members of an association may feel collectively committed, others may act rather as individually-involved agents, or even as pure consumers.

In this section, we consider the different equilibria corresponding to different social modalities of formation of associations that resemble the definition above. We confine our attention to two particular modes of emergence of association where agents choose to act not as individuals, but as members of a group, acting under a "common knowledge of solidarity" (Bacharach, 1999).

In the first mode, the members can decide together to contribute an equal amount. In the second, some members can form a team of contributors. The latter can be likened to the leaders or originators of the association. Thus, using Bacharach's terms, we consider a "we-frame" reasoning, which, in contrast to the "I-frame" reasoning, asks "What should we do?" instead of the more standard "What should I do?" (Bacharach et al., 2006). Depending on the position of the originators or leaders with regard to the action undertaken, one can distinguish between associations "for self" and associations "for others". In the first case, the members self-organize with no distinction between a dominant category of active members and beneficiaries. In the organization "for others", on the contrary, there is a differentiation a priori between categories of so-called "weak" and "strong" agents (Laville and Sainsaulieu, 1997, p. 288.)

These modes of emergence affect the internal functioning of the organization. In associations whose members are not the direct beneficiaries, it is common to observe some detachment of "weak" 
categories from the "strong" actors. In this kind of organization, the mobilization of passive beneficiaries becomes an important issue for management. In self oriented associations, on the contrary, the difficulty consists in reaching a consensus between the "strong actors" and pursuing the joint action in a sustained manner (Laville and Sainsaulieu, 1997, p. 290).

In the model proposed here, these situations are considered using of different concepts of equilibrium. The N-symmetric equilibrium can be considered as the most socially desired result, in that it implies equal contributions from each member. It corresponds to the case of an association where all the participants belong to the same category of actors.

However, following Olson (1971), when an internal group of members forms to make an additional voluntary contribution, for instance "strong" participants in the case of an association "for others", a K-symmetric equilibrium can be achieved. Finally, introducing a budget constraint allows us to analyze a partial K-symmetric equilibrium. In this case, the members belonging to the group of volunteers can each make an equal voluntary contribution, while members whose incomes do not allow them to contribute at the same level contribute less.

\subsection{N-symmetric equilibria: when all are "l" vs "We"}

In the case of $\mathrm{N}$-symmetric equilibrium, the voluntary contribution $d_{i}=d \quad \forall i \in N$ is equivalent to a voluntary increase in dues, raising them from $c$ to $c^{\prime}=c+d$. Here we make an explicit distinction between a $\mathrm{N}$-symmetric equilibrium based on individual isolated decisions ("I-frame" reasoning) and a $\mathrm{N}$-symmetric equilibrium that can result from "We-frame" reasoning. We call these the $I-N$ and We-N symmetric equilibrium respectively.

Definition 3: We define a We-N symmetric equilibrium as an equilibrium in which the $N$ members of an association make a collective decision about the level of their individual voluntary contributions.

Definition 4: We define a I-N symmetric equilibrium as an equilibrium in which the $N$ members of an association make the decision about the level of their individual voluntary contributions individually.

Following Bacharach, a team reasoner $i$ proceeds in two steps that can be expressed as two questions: "what should we do" (as a team) and consequently "what should I do" (as a member of the team). "Step one is to reason at the group level - to engage in profile-based reasoning - and (...) step two is to reason as an individual that because the ith component of the output of stage one is what it is, that's what she should do" (Bacharach et al., 2006, p. 123).

How do members calculate the level of their contributions?

The first order conditions are expressed differently depending on whether agents reason in an Iframe or a We-frame. In the case of the I-frame, the utility function is derived with respect to the individual contribution $\mathrm{d}_{\mathrm{i}}$, and in the We-frame, all individual contributions $\mathrm{d}_{\mathrm{j}}$ are equal within the team and the utility function is thus derived with respect to this common value $\mathrm{d}$ of individual voluntary contributions.

The I-frame corresponds to standard reasoning. Individual utility is expressed by: 
$U_{i}=w_{i}-c-d_{i}+\frac{\theta}{N^{\gamma}}\left(N c+\sum_{j \neq i} d_{j}+d_{i}+X\right)^{\alpha}$,

and its derivative:

$$
\frac{\partial U_{i}}{\partial d_{i}}=-1+\frac{\theta \alpha}{N^{\gamma}\left(N c+\sum_{j \neq i} d_{j}+d_{i}+X\right)^{1-\alpha}}
$$

In the We-frame, because members are in symmetrical positions, the answer to the question "What should we do?" is: to reach a total contribution $D^{*}$ shared equally among the team and which maximizes the individual utility of each member. Then the answer to the question "What should I do?" will be: to contribute at a level $\mathrm{d}^{*}=\mathrm{D} * / \mathrm{N}$.

This time, the individual utility function can be written:

$$
U_{i}=w-c-d+\frac{\theta}{N^{\gamma}}(N(c+d)+X)^{\alpha},
$$

and its derivative:

$$
\frac{\partial U_{i}}{\partial d}=-1+\frac{\theta \alpha N^{1-\gamma}}{(N(c+d)+X)^{1-\alpha}} .
$$

The two expressions (3) and (4) of the derivative of individual utility differ in the power of the size of the association $\mathrm{N}$.

Proposition 3: Without budget constraint, there exists a unique I-N symmetric equilibrium of the voluntary contribution $d^{*}$ whose value is increasing in $\theta$ and $\alpha$ and decreasing in $c$ and $X$.

For $X=0$ (and more widely $X \leq 0$ ), $d^{*}$ is decreasing with $N$.

For $X>0$, there exists a value $N^{*}$ under which $d^{*}$ is decreasing with $N$ and above which $d^{*}$ is increasing with $N$. $N^{*}$ is an increasing function of $\theta$ and a decreasing function of $X$.

Proof is given in Appendix B.

Example: the sign of $d^{*}: d^{*}$ is constrained to a positive or zero value. Due to the concavity of the utility function $(X \geq 0$ and $\alpha \in] 0,1[$ ), a negative value of $d$ resulting from the first order conditions will give $d^{*}=0$ because the utility function is thus decreasing for any $d \geq 0$.

At the limit, $\mathrm{d}=0 \Leftrightarrow \quad c N^{\frac{\gamma}{1-\alpha}+1}+X N^{\frac{\gamma}{1-\alpha}}-(\theta \alpha)^{\frac{1}{1-\alpha}}=0$

To illustrate this, let us take the case where $\gamma=1-\alpha$, then equation (5) becomes

$C N^{2}+X N-(\theta \alpha)^{\frac{1}{1-\alpha}}=0$ (6) that has a negative and a positive root $\bar{N}$.

Thus, $d$ is negative for any size $N<\bar{N}$ and positive for $N>\bar{N}$.

Then, $\mathrm{d}^{*}=0 \quad \forall N \leq \bar{N}$ and $d^{*}>0 \forall N>\bar{N}$. 
Thus, $\vec{N}$ is a threshold above which there exists a N-symmetric equilibrium with positive voluntary contributions.

Proposition 4: In the absence of budget constraint, there exists a unique We- $N$ symmetric equilibrium of voluntary contributions $d^{N}$ whose value is increasing in $N, \theta$ and $\alpha$ and decreasing in $c$ and $X$.

Proof is given in Appendix B.

Illustration: Sign of $d^{N}$. Let us consider the case where $\alpha=2 / 3$ and $\gamma=1 / 3$ (thus $\gamma=1-\alpha$ ).

$\mathrm{d}=0 \Leftrightarrow\left(\frac{2}{3}\right)^{3} N^{2}-C N-X=0$

Equation (7) admits a negative and a positive $\operatorname{root}^{\stackrel{5}{N}}$. Thus $d$ is negative when $N>\stackrel{=}{N}$.

Then, $\stackrel{=}{N}$ represents the threshold above which a "We-N" team tends to generate a positive voluntary contribution.

\section{Proposition 5: We-N versus I-N equilibrium}

For any size of the association, a We-N symmetric equilibrium gives rise to higher voluntary contributions than an I-N one.

Proof is given in Appendix B.

The considerations above concern the choice of the size of the association. Members may have incentives to recruit new members rather than reducing their dues, which might also mean reducing the scope of the collective action. This may be the case for the organizations Olson wrote about, which almost always welcome newcomers (Olson, 1971, p. 59.) Depending on the level of dues and on the structure of distribution of agents' income, it may be more or less difficult to attract new members. Furthermore, when there are criteria for joining an association, this may limit its accessibility to potential members. Gordon and Babchuk (1959), who studied these membership criteria, identified the criteria of merit (as in the American Sociological Society, for instance) and the criteria of attributes, such as gender (e.g. feminist associations), origins or culture (for instance an association of Ukrainians), or simply certain social links between members.

Some associations may, on the contrary, prefer to restrict entry, like the so-called "status organizations" (Hansmann, 1986), which grant their participants a certain social status (Gordon and Babchuk, 1959.) In these organizations, the decision of an individual to join depends not only on the characteristics and the price of the collective good provided, but also on the characteristics of the members. This kind of association establishes a minimal status level (in social, economic or other terms) in addition to membership dues. When membership in an organization provides its members with social status, members may decide to limit the number of newcomers. This is the case described by Olson (1971): 
"If the top " 400 " were to become the top " 4000 ", the benefits to the entrants would be offset by the losses of old members, who would have traded an exalted social connection for one that might be only respectable" (Olson, 1971, p. 37.)

In any case, there exists a trade-off between the size of the organization and the level of dues.

\subsection{K-Symmetric Equilibrium: Who are "We"?}

We shall now consider a so-called "We-frame" context, where the coordinated initiative of a group of $K$ members decides collectively to make a symmetric voluntary contribution. Generally, such coordination is difficult to achieve and the organization costs can be high. However, in some cases an existing group which has already met the organization costs may facilitate further collective action (Olson, 1971, Ross, 1972, Coleman, 1988). As pointed out in the literature (Auman and Dreze, 1974), the aptitude of a group to provide a collective good can be partly explained by its origins and the factors that sustain it. The idea that pre-existing organizations can facilitate the collective action has been suggested by Coleman (1988) in the form of the concept of social capital.

Groups of individuals who desire to contribute more can have various different origins. Besides a pre-existing organization, they may be founded on kinship links or shared social and cultural characteristics or representations.

Definition 4: We define a We-K symmetric equilibrium as an equilibrium in which $K<N$ members of an association make a collective decision about the level of their individual voluntary contributions while the other members decide their individual contribution individually.

Proposition 6: For any $K \leq N$, there exists a unique We-K symmetric equilibrium such that $d_{i}=d^{K} \quad \forall i \in K$, and $d_{j}=0 \forall j \in(N-K)$. Moreover, $d^{K}$ is increasing in $K, \theta$, and $\alpha$ and decreasing in $N, X$, and $c$.

The proof is given in Appendix B.

Example Sign of $d^{K}$ :

$$
d^{K}=0 \Leftrightarrow \frac{(\theta \alpha K)^{\frac{1}{1-\alpha}}}{N^{\frac{\gamma}{1-\alpha}}}-N c-X=0 .
$$

In the case of $\gamma=1-\alpha,(8)$ can be written:

$$
N^{2} C+X N-(\theta \alpha K)^{\frac{1}{1-\alpha}}=0 .
$$

Equation (9) has a negative and a positive root denoted $\tilde{N}^{K}$

$$
d^{K}<0 \text { if } N<\tilde{N}^{K}
$$


$d^{K}>0$ if $N>\tilde{N}^{K}$.

Thus, $\tilde{N}^{K}$ is the threshold above which a K-team brings a positive voluntary contribution.

The propositions 3, 4 and 6 postulate, respectively, that at N-symmetric and K-symmetric equilibria, the voluntary contribution decreases with an increase in the external resources $X$. This result illustrates the effect of crowding out currently highlighted by the models of "pure altruism" (Andreoni, 1988), where individuals are interested in total provision of the public good. As has been shown in a number of theoretical studies, under the "purely altruistic preferences" assumption, voluntary contributions are completely crowded out by public subsidies (Andreoni, 1988, 1990, Ribar and Wilhelm, 2002). However, this assumption has been challenged by empirical facts, notably in the nonprofit area (Steinberg, 1987, Andreoni, 1988, 1990, Ribar and Wilhelm, 2002). The assumption of "impurely altruistic preferences" (Andreoni, 1988), according to which individuals derive utility not only from total provision of the public good, but also from the act of giving, accounts better for the persistence of voluntary contributions in the presence of public financial support. Under this assumption, the crowding-out of voluntary contributions is incomplete (see for instance Steinberg, 1987.) Moreover, Rose-Ackerman (1986) shows the possible crowdingin effect of government grants in situations where voluntary contributions and grants are not perfect substitutes. However, in her model, crowding-in effects are only possible under the condition that the government is able to impose its rules on the organizations it supports concerning the services they provide.

The result that voluntary contributions are increasing in $\theta$ describes the positive effects of the attractiveness of the public good on individual incentives to contribute. This theoretical finding is supported by a number of experimental studies, where an increase in the parameter of attractiveness leads to an increase in the mean of voluntary contributions, but not necessarily at the individual level of each subject (Hichri and Kirman, 2007).

Finally, according to the proposition above, $K$ agents forming an internal team may decide to contribute an equal amount while others pay only the compulsory dues. The voluntary contribution decreasing in $N$ sheds light on the character of the sharing between the members of the team and the rest of the group. Given the size $K$ of the team of volunteers, the amount of their effort $d^{K}$ being decreasing with $N$, means that the incentive to contribute is smaller as the team of volunteers is small compared to the size of the association. Conversely, given $N, d^{K}$ is increasing with the size $K$ of the team of volunteers, thus when the team may gather a growing share of the population.

Individuals may be averse to sharing a common good among a large number of people when a public good is congestible (Alesina and La Ferrara, 2000, Bergstrom and Goodman, 1973). As Ahn et al. (2009) showed, individuals contribute greater amounts for the provision of collective goods in restricted-entry groups than in free-entry groups. In these restricted-entry groups, the selection of newcomers by members leads to an increase in contributions and earnings.

In the real world, homophile preferences and the size and composition of the population lead to the formation of homogeneous groups (Cohen, 1977; Popielarz and McPehrson, 1995). Social structure can constrain or favor individual choices based on homophile preferences (McPherson and Lovin 1987). Therefore, among the factors influencing the internal teams in associations, we should distinguish between constrained and freely-chosen homophily.

We shall incorporate this idea into our model in the last section of this paper, by introducing individual preferences for the subjective quality of the public good. 


\section{Voluntary contributions and heterogeneity of incomes}

Going one step further, this section aims to introduce the impact of heterogeneity of incomes on the formation of teams of volunteers within associations. Heterogeneity of the agents' economic power has to be taken into account through two complementary aspects: the budget constraints and the fact that marginal contribution of one monetary unit to the individual utility depends on the level of income. We will introduce these two aspects successively into our model.

\subsection{Budget constraint and partial K-symmetric equilibrium: a We-frame for the richest}

Here, we introduce some heterogeneity by imposing the budget constraint that influences agents' choices. In the case with budget constraint, members of the association are constrained to a level of contributions that cannot exceed the level of $\bar{d}_{i}$ limited by their income $w_{i}$.

This may result in a team-based equilibrium in which only contributions of a share $K$ of the total population $N$ are symmetric.

Proposition 7: Given a distribution of incomes, there exists a unique value of $K \leq N$ and a unique We-K symmetric equilibrium, such that $d_{i}=d^{K} \quad \forall i \in K=\left\{k \mid w_{k}-c-d^{K} \geq 0\right\}$ and $d_{j}=w_{j}-c$ $\forall j \in(N-K)$.

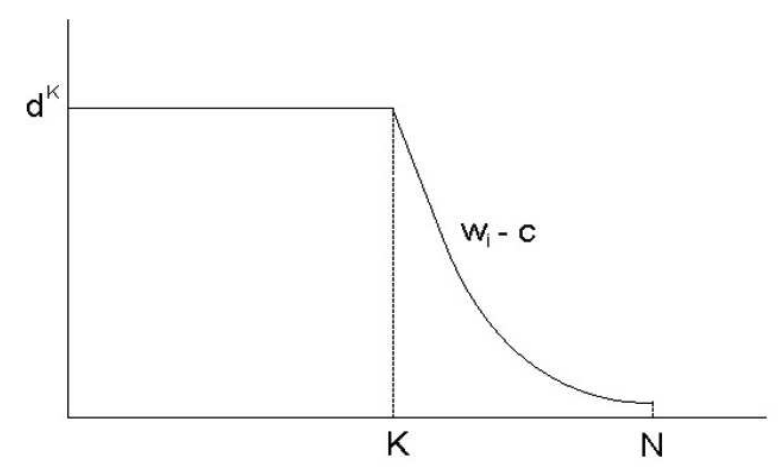

The proof is given in Appendix C.

\subsection{Heterogeneity of incomes and non-symmetric equilibrium: We-frame and price discrimination}

In this section, we study the relation between the level of voluntary contributions and incomes by introducing the non-constant character of the marginal contribution of a monetary unit to the individual utility. Taking the individual utility model based on division of the budget between private consumption and contributions to the public good, we can consider that the net income of the agent $i$, or $w_{i}-c-d_{i}$ contributes to her utility in a concave way. Consequently, we can note:

$$
U_{i}=\left(w_{i}-c-d_{i}\right)^{\beta}+\frac{\theta}{N^{\gamma}}\left(N c+\sum_{j=1}^{N} d_{j}+X\right)^{\alpha} .
$$


Proposition 8: There exists a unique equilibrium under constraint, in which the richest agents of a sub-group $K \leq N$ contribute at such a level that their net incomes are reduced to a common reference level $w_{i}-c-d_{i}=w_{0}>0$ for all the agents in $K$, while the agents from $N-K$, whose incomes are less than $w_{0}+c$, do not make any voluntary contributions.

For proof see Appendix C.

Proposition 8 shows how the agents choose their level of voluntary contribution at a non-symmetric equilibrium. In fact, in this case, each agent pays a personalized price for the public good. The ability of voluntary organizations to establish personalized prices (or a system of price discrimination) has already been stressed in the economic literature (Hansmann, 1981, Ben-Ner, 1986.) According to Ben-Ner, the non-market interactions between members, (kinship links, neighborhood, common background), as well as the non-profit distribution constraint, allow these organizations to reveal demands and to establish personalized prices.

The result where all the agents are reduced to the same level $w_{0}$ of net income is somewhat simplistic. This is due to the fact that in this model, the share of the initial allocation dedicated to private consumption corresponds to an homogenous good with a unique technology of consumption. However, in real life, disposable income is rather devoted partly to differentiated baskets of goods characterized by diversified consumption technologies and partly to savings.

\section{Volunteering and subjective quality: The I for the We and the I for the I}

Now, let us assume that the agents can contribute to the public good not only money, but also their time and effort. One can differentiate three main types of theoretical framework for explaining volunteering: pure public good models, private consumption models and investment models (Ziemek, 2006.) Pure public good models consider that volunteers are motivated exclusively by total provision of the public good. Private consumption models focus on personal rewards, like social status or simply a warm glow. Investment models may be considered as a special case of private consumption model, as volunteering provides certain benefits associated with the accumulation of human and social capital.

The model we describe below is situated between the "pure public goods" and "private consumption" approaches, as the act of volunteering is not independent of the characteristics of the public good to which it contributes. We consider that volunteering provides an additional utility to the one derived from total provision, as in Steinberg (1987), for instance. Steinberg's approach, considered as a "mixed public-private good approach", represents a case of an "impurely altruistic model" (Andreoni, 1990). The individual utility function includes the public goods provided through the agent's individual voluntary contribution, public resources and the contributions of others. The individual contribution and the other agents' contributions are complementary when the individual is faced with social comparisons within her group of reference. When the individual is motivated only by total provision, her contributions and the contributions of others are perfect substitutes. 
In our model, each member $i$ can contribute to the public good by making a non-monetary contribution of effort noted $v_{i}$, which is subjective in value and which adds to her monetary contribution $d_{i}$. This effort allows agents to influence the quality of the public good according to their own preferences. The quality is subjective insofar as it cannot always be evaluated objectively. In other words, the quality of a good (or a service) is subjective when it is evaluated through individual perceptions rather than standardized measures.

One notable example of the use of subjective quality comes from the field of child day-care. Here, the measurement of quality is influenced by parents' preferences concerning certain service characteristics, making it more subjective than the standards elaborated by experts. For instance, it may be important to know whether the provider of the child-care service speaks the same language, shares the same values or the same religion. This implies that an individual's perception of quality may differ not only from others' perceptions, but also from the more objective evaluations made by experts using an index of quality (Farquhar, 1993, Moss, 1994.) In fact, as Evers and Riedel (2004) have shown in a German case study, the development of nonprofit child-care centers was mainly driven by the desire of some parents to create a service in keeping with certain pedagogical, ideological or religious principles. As observed in the United States, nonprofit child-care centers tend to include parent participation and provide more labor-intensive services than private ones (Kushman, 1979).

We therefore suggest that the members of an association can volunteer in the hope of influencing the subjective quality of the good or service being provided. Bearing in mind the example of child care, the role of volunteers can consist in organizing activities according to their cultural background or educational convictions. In the field of the arts, active members can influence programming choices according to their personal tastes. Finally, in a charity helping the poor, the more active volunteers can influence the criteria of eligibility or the order of priority (RoseAckerman, 1986.)

Two aspects must be taken into consideration here:

- The cost of the effort.

By convention, we measure effort $v_{i}$ as a fraction of the individual's disposable time that is dedicated to the volunteering, or $v_{i} \in[0,1]$. For $i$, the effort $v_{i}$ represents an opportunity cost that is proportional to her income. We assume that each agent $i$ works a length of time 1 to earn an income $w_{i}$. Thus, the opportunity cost can be written as $v_{i} w_{i}$.

- The impact on the subjective value of the good.

The subjective value of the public good for the agent $i$ depends both on the total amount of effort provided by all the volunteers and on the weight of her own effort as a proportion of the total. The combination of both can differ according to how "individualistic" the association is. So agents can attach more or less value to the public good itself, but they also value their own contributions more or less highly.

Thus, the subjective level of effort can be written as follows:

$$
(1-\delta) \sum_{j=1}^{N} v_{j}+\delta v_{i}=(1-\delta) v_{-i}+v_{i}
$$

where $\delta$ is the parameter of "individualism". Two extreme cases can be considered:

- $\delta=0$ leads to $\sum_{j=1}^{N} v_{j}$ and expresses a purely collective orientation. In other words, the effort of a volunteer is added to the sum of efforts provided by other agents; efforts are pure substitutes. 
- $\delta=1$ leads to $v_{i}$ and designates a purely individualistic orientation, where the personal contribution is the only one valued, in spite of the effort provided by others.

We consider that $\delta$, the so-called parameter of individualism, characterizes the type of association. Under some conditions, it is possible to link this parameter with the typology of voluntary associations (see for instance Gordon and Babchuk, 1959), defining them as "expressive" or "instrumental groups". The main objective of the first type of association is to provide common activities for their members. The members are direct beneficiaries of organized activities (for instance a country-club.) A $\delta$ equal to one denotes a purely expressive association, inasmuch as participation in its activities provides a direct gratification for the members. On the contrary, the main function of so-called instrumental associations is directed outside the organization. This kind of association aims to create and maintain a normative condition or a commitment (Gordon and Babchuk, p. 25) and exercises a social influence. Examples include associations for the defense of the rights of minorities and the poor, or certain political and religious organizations. The extreme case of such an association is denoted by a value of $\delta$ equal to zero. In other words, it is assumed that the members are driven by ideological principles or common values, rather than the pleasure of participating in a shared activity. In real life, voluntary associations can accomplish both functions. For example, some associations may have an expressive function at the local level and an instrumental function at the national level. Intermediate associations may be situated between the two extreme cases with a $\delta$ more or less close to 0 or to 1 .

In our model, we introduce effort into the production function of the public good by means of a Cobb-Douglas function. The utility of the agent $i$ is now written as:

$$
U_{i}=w_{i}-c-d_{i}-w_{i} v_{i}+\frac{\theta}{N^{\gamma}}\left(N c+\sum_{j=1}^{N} d_{j}+X\right)^{\alpha}\left((1-\delta) \sum_{j=1}^{N} v_{j}+\delta v_{i}\right)^{\beta}
$$

with $\alpha$ and $\beta \in] 0,1[$.

In a standard way, each agent $i$ determines her pecuniary contribution $d_{i}$ and her effort $v_{i}$ so as to maximize her subjective utility $U_{i}$, according to her rational expectations about the levels of voluntary contributions $\sum_{j \neq i} d_{j}=d_{-j}$ and effort $\sum_{j \neq i} v_{i}=v_{-i}$ made by the other agents.

Proposition 9: At equilibrium, each agent fixes her levels of voluntary contribution and effort $\left(d_{i}, v_{i}\right)$ by attributing to the latter a relative weight depending on her income. The lower the income, the higher the relative weight of the effort. In other words, a poorer agent will compensate for her weak monetary contribution by a greater effort. Moreover, for all the agents, the level of direct effort is an increasing function of the degree of individualism $\delta$.

For proof see Appendix D.

The model above shows that pecuniary contributions and volunteering can well be made jointly. This conforms to the stylized facts, whereby monetary donations and volunteering often go together (Cappellari et al., 2011). One of explanations is that motivated by "warm glow", donors need to control the use of their donations. In our model, we stress the idea that the trade-off between monetary contributions and volunteering can also be based on the desire to influence the quality of the public output. Moreover, the valuation of the public good becomes socially-based, to the extent that it depends on the agents' characteristics (culture, education, ideological considerations, etc.)

Pecuniary contributions and volunteering may well influence the characteristics of the good 
differently. The greater the $\delta$ (the parameter of individualism characterizing the association), the greater the effort provided by individual. In other words, the model predicts that volunteering is likely to be more important in expressive associations (Gordon and Babchuk, 1959), i.e., those essentially oriented towards the interests of their members.

This finding is in line with empirical studies on volunteering. Salamon et al. (2003) highlight the important role of volunteers in the field of culture and arts, accounting for a quarter of total volunteering. According to Schervish and Havens (1997), volunteers in the United States largely benefit from the activities they create. In France, more than half of the members of expressive associations (social clubs, etc.) take part in the shared activities as organizers at least once a week, compared with 34 per cent in the instrumental associations. Volunteering is often motivated by specific needs, for example regarding children's education (Prouteau and Wolff 2004; Carlin, 2001; Ziemek, 2006).

As regards the effect of income on volunteering, according to (D.3), the level of effort is a decreasing function of $\mathrm{w}_{\mathrm{i}}$. In other words, the effort of volunteering is likely to rise when the wage rate decreases. An empirical support to this finding was provided by Menchik and Weisbrod (1987), who found an inverse relation between volunteering and wage rates. Moreover, Andreoni et al. (1996) documented a relatively substantial negative effect of the net wage on volunteer hours. However, the effects of wage rate on volunteering may be sensitive to the type of motivation or other determinants.

\section{Conclusion}

In this paper, we have analyzed the voluntary association as a means of collective action. An important feature of these organizations is individual involvement in a common action. We have introduced different ways for individuals to participate in voluntary associations according to the degree of their commitment to collective aims, corresponding to a shift from personal to collective self (Brewer and Gardner, 1996).

We have developed a model of voluntary association formed by individuals interested in obtaining satisfaction from the provision of a common good. We show that the efficiency of collective action is higher when some or all individuals follow "We-frame" reasoning (Bacharach et al., 2006).

The main contribution of this paper consists in highlighting voluntary association as a group of individuals formed around a common goal. In this sense, voluntary associations appear as an archetypal case of team reasoning formation. But this does not exclude that possibility that the members of an association may have their own aspirations and conceptions of the good or service they want to provide. One implication of our findings is that to attract greater volunteering effort, associations should better respond to the personal interests of volunteers. In associations "forothers" this could be achieved through public recognition or prestige, but also through dialogue and communication between members.

An important assumption made in the model is that individuals may desire not only to increase production of the public good, but also to influence its quality through volunteering. The originality of the model is that we assume the public good to be characterized by at least two main components, namely quantity and quality. The quantity is considered here as a purely public component, insofar as all the members benefit equally from it. The quality of the public good is considered as a mixed (public and private) component. The agents can enjoy part of it in the same way, but there may exist certain characteristics of quality that are difficult or impossible to measure 
objectively. In a way, quality is always somewhat subjective, to the extent that perfect correspondence with the preferences of heterogeneous agents is unlikely to occur.

In our model, the agents can contribute money or time and effort. The latter, or volunteering, allows them to influence the quality of the good (or service) provided according to their own preferences. The collective dimension of the self does not efface the personal dimension. This idea is formalized by introducing the concept of subjective quality, whereby the perceptions of the quality of a good (or service) may well differ between individuals. However, this does not exclude other possible motives of volunteers, which are not taken into account here. Moreover, the motives of volunteers to devote time and effort may differ, depending on the people and the social context. The degrees of motivation of individuals can also be heterogeneous. This heterogeneity of motives could be an interesting subject for future work.

Accepting these differences, what has been called "accepted differentiation", allows the actors to promote collective action. As Laville and Sainsaulieu (1997) observed, associative activity is an exercise in social cohesion; it does not exclude the expression of differences that come together around a shared project. In other words, as the saying goes, "people can share the same bed without sharing the same dreams."

\section{Acknowledgments}

The authors gratefully acknowledge Alan Kirman, Michel Grossetti, Walid Hichri, Alain Rallet, and Sylvie Thoron for helpful comments, discussions, and suggestions. 


\section{APPENDICES}

\section{A. Proofs of propositions 1 and 2}

Let us assume first symmetric voluntary contributions, in other words $d_{i}=d$ for each $i$, and note $c^{\prime}=c+d$. Now, the equation (2) can be re-written as

$$
f(N)=\frac{1}{N^{\gamma}}\left(N c^{\prime}+X\right)^{\alpha},
$$

To make $f(N)$ defined and continuous, let us assume that

or that

$$
N c^{\prime}+X \geq 0
$$

$$
N \geq-\frac{X}{c^{\prime}}=N_{0}
$$

When $X<0$ (namely, in the presence of fixed costs), this condition means that the number of participants must be high enough for the sum of individual contributions $c^{\prime}$ to compensate the fixed cost $X$.

When $X \geq 0$, this condition holds for any value of $N \geq 0$.

The derivative of the production function of the public good (A.1) can be written as follows:

$$
\frac{\mathrm{d} f}{\mathrm{~d} N}=\frac{N c^{\prime}(\alpha-\gamma)-\gamma X}{N^{\gamma+1}\left(N c^{\prime}+X\right)^{1-\alpha}} .
$$

Given (A.2), the sign of the derivative will be the one of the numerator (A.3), or

$$
s g \frac{\mathrm{d} f}{\mathrm{~d} N}=\operatorname{sg}\left(N c^{\prime}(\alpha-\gamma)-\not X\right) .
$$

(i.) When $X \geq 0$, namely in the presence of public subsidies,

If $\gamma \geq \alpha$

$$
\frac{\mathrm{d} f}{\mathrm{~d} N} \leq 0, \forall N .
$$

In this case, association does not make sense as the sharing rule described by $\gamma$ cancels the gain of individual utility.

If $\gamma<\alpha$,

The variation of the sign of the derivative is given in the table below.

Table A.1: Variations of the production function with $N$ in the presence of external subsidies

\begin{tabular}{l|lll}
\hline & \multicolumn{3}{|c}{$N_{1}=\frac{\not X}{(\alpha-\gamma) c^{\prime}}}$. \\
\hline$\frac{d f}{d N}$ & $<0$ & 0 & $>0$ \\
\hline
\end{tabular}


Beyond $N_{1}$, each additional contribution leads to a gain in individual utility. There is no overcrowding, but there exists a minimal size of association which is necessary for association to make sense.

(ii.) When $X<0$, namely in the presence of fixed costs, two cases need to be studied:

If $\gamma \leq \alpha$, the production function is increasing with the number of contributors if their number is higher than $N_{0}$. In this case, there is no overcrowding.

$$
N c^{\prime}(\alpha-\gamma)-\gamma X>0, \forall N \text {. }
$$

Thus,

$$
\frac{\mathrm{d} f}{\mathrm{~d} N} \geq 0, \forall N \geq \frac{-X}{c^{\prime}}=N_{0} .
$$

If $\gamma>\alpha$,

$$
N c^{\prime}(\alpha-\gamma)-\gamma X=0
$$

for a number of participants $N$ equal to

$$
N_{1}=\frac{-\gamma X}{(\gamma-\alpha) c^{\prime}}
$$

the table of variations of the derivative will be the following:

Table A.2: Variations of the production function with $N$ in the presence of fixed costs

\begin{tabular}{l|ccc}
\hline$N$ & $N_{1}=\frac{-\gamma X}{(\gamma-\alpha) c^{\prime}}$. \\
\hline$\frac{d f}{d N}$ & $>0$ & 0 & $<0$ \\
\hline
\end{tabular}

Beyond $N_{1}$, the production function generates overcrowding. In other words, when the number of participants is higher than $N_{1}$, the amount of good produced diminishes with the number of members.

Note that $N_{1}>N_{0}$. The number of members $N_{0}$ represents a minimal size of association. Beyond this size and up to $N_{1}$, effects of overcrowding are absent, namely the production of the public good increases with the number of members.

\section{A.1 Extension 1}

Now let us suppose that $K$ first members, founders for instance, have fixed the level of the voluntary contribution, while the newcomers contribute only the compulsory amount $c$. For each $N \in\left[N_{0}, K\right]$, the previous results hold.

Beyond this threshold, $\forall N>K$ the production function is written as follows:

$$
f(N)=\frac{1}{N^{\gamma}}(N c+K d+X)^{\alpha} .
$$

This situation is equivalent to the previous case with $c^{\prime}=c$ and

$$
Y=X+K d \text {. }
$$


Thus, the previous results are found with

$$
N_{0}=-\frac{Y}{c}
$$

and

$$
N_{1}=\frac{\gamma Y}{(\alpha-\gamma) c}
$$

An important issue here is to situate $N_{1}$ with regard to $K$.

If $Y \geq 0$ and $\gamma<\alpha$,

$$
N_{1}=\frac{\gamma Y}{(\alpha-\gamma) c} \geq K
$$

if and only if

$$
\gamma Y \geq(\alpha-\gamma) c K
$$

By substituting (A.11) in (A.13) we obtain

$$
K[c(\alpha-\gamma)-d] \leq \gamma X .
$$

- If the term of the equation (A.14) $c(\alpha-\gamma)-d>0$, i.e. if the compulsory amount is high enough relative to voluntary contributions, then we obtain

$$
K<\frac{\gamma X}{c(\alpha-\gamma)-d}=s \text {. }
$$

\begin{tabular}{|c|c|c|c|c|c|}
\hline & & & & & \\
\hline & & $K$ & & & \\
\hline$d f$ & $<0$ & $>0$ & $<0$ & $<0$ & $>0$ \\
\hline & & & & & \\
\hline$\frac{d f}{d N}$ & $<0$ & $>0$ & & & \\
\hline
\end{tabular}

Therefore we obtain the following table of variations, where two alternative cases depend on the relative position of $K$ with regard to $S$.

Table A.3: Position of $K$ relatively to $s$

Thus, for a population that is large enough, there is no overcrowding.

- In the case where $c(\alpha-\gamma)-d \leq 0$ and $X \geq 0$, the inequality (A.14) holds for any

$K \geq 0$ (here we are in the alternative case $K \leq N_{1}$ ).

If $X<0$, we find the two alternative cases above.

Finally, if $Y<0$, we find the previous results.

\section{A.2 Extension 2}

If beyond the number $K$ it is possible to make voluntary contributions, the situation of every member is improved. Overcrowding remains absent, but it can occur when $Y<0$ and $\gamma>\alpha$, beyond a threshold possibly moved forward. 


\section{A.3 Extension 3}

If below $K$, the voluntary contributions vary, one can substitute $K d$ by $D=\sum_{j=1}^{K} d_{j}$. The result still holds.

\section{B. Proofs of propositions 3 to 6}

\section{B.1 Proof of proposition 3}

Given the utility function

$$
\begin{aligned}
& U_{i}=w_{i}-c-d_{i}+\frac{\theta}{N^{\gamma}}\left(N c+\sum_{j \neq i} d_{j}+d_{i}+X\right)^{\alpha}, \\
& \frac{\partial U_{i}}{\partial d_{i}}=-1+\frac{\theta \alpha}{N^{\gamma}\left(N c+\sum_{j \neq i} d_{j}+d_{i}+X\right)^{1-\alpha}} \text { (B.2) }
\end{aligned}
$$

The first-order condition for a $\mathrm{N}$-symmetric equilibrium gives the optimal value of voluntary contributions without budget constraint ${ }^{2}$.

$$
d^{*}={\frac{(\theta \alpha)}{N^{\frac{\gamma}{1-\alpha}+1}}}^{\frac{1}{1-\alpha}}-\frac{X}{N}-c .
$$

From equation (B.3) follows that $d^{*}$ is decreasing in $\mathrm{X}$ and $\mathrm{C}$ and increasing in $\theta$ and $\alpha$. The variations of $\mathrm{d}^{*}$ with $\mathrm{N}$ depend on the sign of the derivative

$$
\frac{\partial d^{*}}{\partial N}=-\left(\frac{\gamma}{1-\alpha}+1\right) \frac{(\theta \alpha)^{\frac{1}{1-\alpha}}}{N^{\frac{\gamma}{1-\alpha}+2}}+\frac{X}{N^{2}}
$$

If $\mathrm{X} \leq 0 \frac{\partial d^{*}}{\partial N}<0 \quad \forall \mathrm{N}$ then $\mathrm{d}^{*}$ is a decreasing function of $\mathrm{N}$.

If $\mathrm{X}>0$ 列 $\frac{\partial d^{*}}{\partial N}=0 \quad \Leftrightarrow \mathrm{N}=\left[\theta \alpha\left(\frac{1+\frac{\gamma}{1-\alpha}}{X}\right)^{1-\alpha}\right]^{\frac{1}{\gamma}}=\mathrm{N}^{*}$

$\mathrm{d}^{*}$ is a decreasing function in $N$ for $N<N^{*}$

and increasing with $N$ for $N>N^{*}$

where $N^{*}$ is a growing function of $\theta$ and decreasing function of $X$.

\section{B.2. Proof of proposition 4}

In a We-frame the utility function for any $i \in N$ can be written as follows

$$
U_{i}=w-c-d+\frac{\theta}{N^{\gamma}}(N(c+d)+X)^{\alpha}, \text { and }
$$

\footnotetext{
${ }^{2}$ The second order conditions hold if $X \geq 0$ and $\alpha<1$.
} 


$$
\frac{\partial U_{i}}{\partial d}=-1+\frac{\theta \alpha N^{1-\gamma}}{(N(c+d)+X)^{1-\alpha}}
$$

The F.O.C. gives $c^{N}=d^{N}+c=(\theta \alpha)^{\frac{1}{1-\alpha}} N^{\frac{\alpha-\gamma}{1-\alpha}}-\frac{X}{N}$.

Following the assumption $\mathrm{X} \geq 0, d^{N}$ is an increasing function of $\mathrm{N}$ and a decreasing function of $\mathrm{X}$.

\section{B.3 Proof of proposition 5}

Denote $\mathrm{c}^{*}=\mathrm{d}^{*}+\mathrm{c}$ for the I-frame equilibrium and $c^{N}=d^{N}+c$ for the We-frame one.

$$
c^{N}>\mathrm{c}^{*} \Leftrightarrow N^{\frac{\alpha-\gamma}{1-\alpha}}>\frac{1}{N^{\frac{\gamma}{1-\alpha}+1}} \text { provided that } 0<\gamma<\alpha<1 \Leftrightarrow N^{\alpha-\gamma}>\frac{1}{N^{1-(\alpha-\gamma)}} \Leftrightarrow 1>\frac{1}{N}
$$

\section{B.4 Proof of proposition 6}

The proof proceeds in two steps.

First, let us consider the K-team. Members of the team determine a level of contribution $d^{K}$ maximizing the individual utility of each of them.

Denote $d$ the individual voluntary contribution of the team's members, then their utility function can be written:

$$
\forall i \in K \quad U_{i}=w_{i}-c-d+\frac{\theta}{N^{\gamma}}(N c+K d+X)^{\alpha},
$$

under the rational expectation that members outside the K-team do not bring any contribution over and above the compulsory amount $\mathrm{c}$.

Maximizing (B.4) yields

$$
\begin{aligned}
& N c+K d^{K}+X=\left(\frac{K \theta \alpha}{N^{\gamma}}\right)^{\frac{1}{1-\alpha}} \\
& \text { thus } \quad d^{K}=\frac{\left(\frac{\theta \alpha K}{N^{\gamma}}\right)^{\frac{1}{1-\alpha}}-N c-X}{K} .
\end{aligned}
$$

To show that this actually defines an equilibrium, it is then necessary to validate the above rational expectation.

Let us consider the individuals outside the K-team:

$\forall i \in N-K, \quad U_{i}=w_{i}-c-d_{i}+\frac{\theta}{N^{\gamma}}\left(N c+K d^{K}+d_{i}+d_{-i}+X\right)^{\alpha}$,

where $d_{-i}=\sum_{j \in N-K, j \neq i} d_{j}$.

FOC give $d_{i}=\left(\frac{\theta \alpha}{N^{\gamma}}\right)^{\frac{1}{1-\alpha}}-\left(N c-K d^{K}+X\right)-d_{-i}$,

where $d_{-i}>0$ iff $\exists j \in N-K: d_{j}>0$ and $d_{-i}=0$ conversely. 
By substituting (B.5) in (B.8) provided $\mathrm{K}>1, \alpha<1$, and thus $K^{\frac{1}{1-\alpha}}>1$, $d_{i}=\left(\frac{\theta \alpha}{N^{\gamma}}\right)^{\frac{1}{1-\alpha}}-\left[1-K^{\frac{1}{1-\alpha}}\right]-d_{-i}$, and then $\mathrm{d}_{\mathrm{i}}<0$.

Thus, $i$ does not bring any (positive) voluntary contribution, validating the expectation of the members of the K-team.

From (B.6) it follows that $d^{K}$ is increasing in $\theta, \alpha$, and $K$ and decreasing in $N, X$, and $c$.

\section{Proofs of the propositions 7 and 8}

\section{C.1 Proof of proposition 7}

Let us rank the population of agents in decreasing order of incomes as follows: $j>i \Rightarrow w_{j} \leq w i$.

The result is a straightforward consequence of the properties shown by Foray, Thoron, and Zimmermann (2007) applied to the previous model of equilibrium with constraints. The distribution of voluntary contributions is as follows

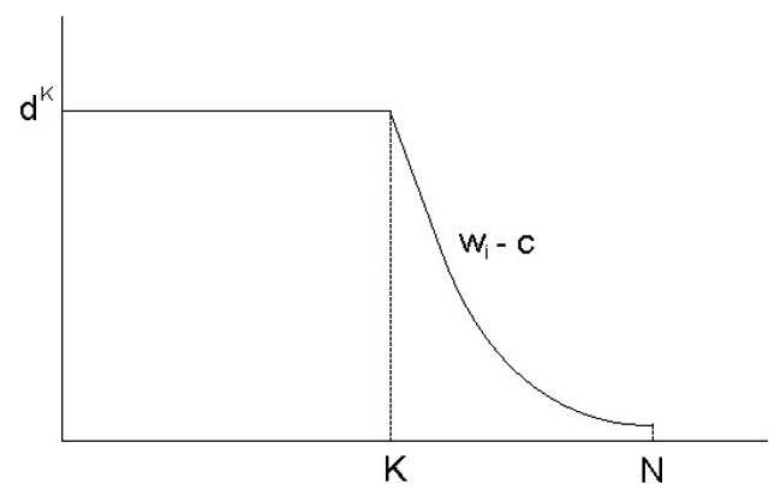

Now, the individual utility is written for any $i \in K$ as follows:

$$
U_{i}^{K}=w_{i}-c-d^{K}+\frac{\theta}{N^{\gamma}}\left(N c+K d^{K}+D^{N-K}+X\right)^{\alpha},
$$

where

$$
D^{N-K}=\sum_{j>K} w_{j}-c
$$

or

$$
U_{i}^{K}=w_{i}-c-d^{K}+\frac{\theta}{N^{\gamma}}\left(K\left(c+d^{K}\right)+\Omega^{N-K}+X\right)^{\alpha},
$$

where

$$
\Omega^{N-K}=\sum_{j \in(N-K)} w_{j}
$$

For any $i \in K$,

$$
\frac{\partial U_{i}}{\partial d^{K}}=-1+\frac{\theta \alpha K}{N^{\gamma}}\left(K\left(c+d^{K}\right)+\Omega^{N-K}+X\right)^{\alpha-1} .
$$


By assuming $\frac{\partial U_{i}}{\partial d^{K}}=0$, we obtain an optimal value of contributions for any $i \in K$ :

$$
d^{K}=\left[\left(\frac{\theta \alpha K}{N^{\gamma}}\right)^{\frac{1}{1-\alpha}}-\Omega^{N-K}-X\right] \frac{1}{K}-c .
$$

According to Foray, Thoron and Zimmermann (2007), the value of $K$ is adjusted in such a way, that $w_{k}-c \geq d^{K}$ and $w_{K+1}-c<d^{K}$.

\section{C.2. Proof of proposition 8}

The proof proceeds in two steps.

In the first step, we compute the individual levels of contribution without any constraint. Then in the second step, we introduce budget constraints and the necessity for voluntary contributions to be positive or zero.

\section{Step 1: Contributions without budget constraint}

Now, the first order condition is written as

$$
\frac{\partial U_{i}}{\partial d_{i}}=-\frac{\beta}{\left(w_{i}-c-d_{i}\right)^{1-\beta}}+\frac{\theta}{N^{\gamma}} \frac{\alpha}{\left(N c+\sum_{j=1}^{N} d_{j}+X\right)^{1-\alpha}} .
$$

The second order condition becomes

$$
\frac{\partial^{2} U_{i}}{\partial d_{i}^{2}}=-\frac{\beta(1-\beta)}{\left(w_{i}-c-d_{i}\right)^{2-\beta}}-\frac{\theta}{N^{\gamma}} \frac{\alpha(1-\alpha)}{\left(N c+\sum_{j=1}^{N} d_{j}+X\right)^{2-\alpha}}<0 .
$$

The non-constrained equilibrium is obtained by assuming $\frac{\partial U_{i}}{\partial d_{i}}=0 \quad \forall i \in N$ under condition

$$
w_{i}-c-d_{i}>0 \text {. }
$$

We obtain therefore

$$
\frac{\beta}{\left(w_{i}-c-d_{i}\right)^{1-\beta}}=\frac{\theta}{N^{\gamma}} \frac{\alpha}{\left(N c+\sum_{j=1}^{N} d_{j}+X\right)^{1-\alpha}} .
$$

It follows consequently that $\forall i \neq j$

$$
\frac{\beta}{\left(w_{i}-c-d_{i}\right)^{1-\beta}}=\frac{\beta}{\left(w_{j}-c-d_{j}\right)^{1-\beta}}
$$

or that $\forall i \in N, w_{i}-c-d_{i}=w_{0}$, and thus

$$
d_{i}=w_{i}-w_{0}-c .
$$

Thus, after voluntary contribution, all the agents are brought to the same level of net income $w_{0}$.

Now, we can write

$$
\sum_{j=1}^{N} d_{j}=\sum_{j=1}^{N} w_{j}-N\left(c+w_{0}\right)=\Omega-N\left(c+w_{0}\right),
$$

from which, by substituting in (D4) we obtain 


$$
\frac{\beta}{w_{0}^{1-\beta}}=\frac{\theta}{N^{\gamma}} \frac{\alpha}{\left(\Omega+X-N w_{0}\right)^{1-\alpha}}
$$

It follows that $w_{0}$ solution of the implicit equation (C.10) is strictly positive, which satisfies the condition (C.7).

\section{Step 2 : Budget constraints}

We now introduce budget constraints: $\forall i \in N, d_{i} \geq 0$ and $d_{i} \leq w_{i}-c$. In a solution under constraint, $d_{i}<0$ becomes $d_{i}=0$, while $d_{i}>w_{i}-c$ becomes $d_{i}=w_{i}-c$.

Nevertheless, $d_{i}>w_{i}-c \Leftrightarrow w_{i}-c-w_{0}>w_{i}-c$ and thus $\Leftrightarrow w_{0}<0$, which contradicts the previous assertion.

Thus the constraint $d_{i} \geq 0$ still remains.

Here $d_{i}<0$ if and only if $w_{i}<w_{0}+c$, and the set of agents with incomes lower than $\mathrm{w}_{0}+\mathrm{c}$ do not make any voluntary contribution at all.

As in Foray, Thoron, and Zimmermann (2007), if the $N$ agents are ranked in decreasing order of incomes, there exists a $K \leq N$ satisfying the following conditions:

The individual utility is written $\forall i \in K$

$$
U_{i}=\left(w_{i}-c-d_{i}\right)^{\beta}+\frac{\theta}{N^{\gamma}}\left(N c+\sum_{j=1}^{K} d_{j}+X\right)^{\alpha} .
$$

In the same way as above, $\forall i \in K$

$$
d_{i}=w_{i}-w_{0}-c .
$$

However, this time

$$
\sum_{j=1}^{K} d_{j}=\sum_{j=1}^{K} w_{j}-K\left(c+w_{0}\right)=\Omega_{K}-K\left(c+w_{0}\right),
$$

and consequently, $w_{0}$ is solution of the implicit equation

$$
\frac{\beta}{w_{0}^{1-\beta}}=\frac{\theta}{N^{\gamma}} \frac{\alpha}{\left(\Omega_{K}+X-K w_{0}+(N-K) c\right)^{1-\alpha}} .
$$

\section{Proof of proposition 9}

To simplify the expression of the utility function, let us note $w=w_{i}, m=d_{i}, M=N c+X+d_{-i}$, $f=v_{i}, F=(1-\delta) v_{-i}, z=\frac{\theta}{N^{\gamma}}$ and $x=w_{i}-c-d_{i}$. The latter represents the share of the budget of $i$ available for her private consumption.

Thus, the agent $i$ is solving the following:

$$
\operatorname{Max} U(x, m, f)=x-w f+z(M+m)^{\alpha}(F+f)^{\beta}
$$

under a budget constraint

$$
x+m+c-w=0
$$

Using the Kuhn and Tuker theorem and noting the multiplicator corresponding to the constraint (D.2) as $\lambda$, we write the marginal utilities and the respective first order conditions (the marginal utilities are proportional to the prices): 


$$
\begin{gathered}
\frac{\partial U}{\partial x}=1=\lambda p_{x}=\lambda \quad(i) \\
\frac{\partial U}{\partial m}=\alpha z \frac{(F+f)^{\beta}}{(M+m)^{1-\alpha}}=\lambda p_{m}=\lambda \quad(i i),
\end{gathered}
$$

and

From $(i)$ it follows that $\lambda=1$.

$$
\frac{\partial U}{\partial f}=\beta z \frac{(M+m)^{\alpha}}{(F+f)^{1-\beta}}-w=\lambda p_{f}=0 .
$$

Consequently, the first order conditions (ii) and (iii) can be written as

$$
\alpha z(F+f)^{\beta}=(M+m)^{1-\alpha} \quad\left(i i^{\prime}\right)
$$

and

$$
\beta_{z}(M+m)^{\alpha}=w(F+f)^{1-\beta} \quad\left(i i i^{\prime}\right)
$$

By making a cross product of the terms of these equations, we obtain:

$$
\begin{aligned}
& \alpha w(F+f)=\beta(M+m) \\
& \Leftrightarrow \quad f=\frac{\beta}{\alpha w}(M+m)-F .
\end{aligned}
$$

\section{References}

Ahn T.K., Isaac R.M., Salmon T.C. 2009. Coming and going: Experiments on endogenous group sizes for excludable public goods. Journal of Public Economics, 93, 336-351.

Alesina, A., La Ferrara, E. 2000, Participation in Heterogeneous Communities, The Quarterly Journal of Economics, Vol. 115, No 3, 847-904.

Andreoni, J., 1988, Privately Provided Public Goods in a Large Economy: The Limits of Altruism, Journal of Public Economics 35, 57-73.

Andreoni, J. 1989. Giving with Impure Altruism: Applications to Charity and Ricardian Equivalence. Journal of Political Economy, University of Chicago Press, vol. 97(6), pages 1447-58.

Andreoni, J., 1990, Impure Altruism and Donations to Public Goods: a Theory of WarmGlow Giving, The Economic Journal, Vol. 100, Issue 401, 464-477.

Andreoni, J. 1993. An Experimental Test of the Public-Goods Crowding-Out Hypothesis, American Economic Review, American Economic Association, vol. 83(5), pages 1317-27

Andreoni J., 1995, Cooperation in Public Goods Experiments: Kindness and Confusion, American Economic Review, 85(4), 891-904.

Andreoni, J., Gale, W., Scholz, J., 1996. Charitable Contributions of Time and Money, University of Wisconsin-Madison. Department of Economics. Manuscript.

Andreoni, J., Petrie, R., 2004. Public Good Experiments without Confidentiality: A Glimpse into Fund-Raising. Journal of Public Economics, 1605- 1623.

Andreoni, J., Payne, A., 2003. Do Government Grants to Private Charities Crowd Out Giving or Fund-raising? The American Economic Review, 792-812. 
Andreoni J., Payne A., 2011. Is crowding out due entirely to fundraising? Evidence from a panel of charities. Journal of Public Economics 95, 334-343.

Auman, R.J., Dreze, J.H., 1974. Cooperative Games with Coalition Structures. International Journal of Game Theory, Vol.3, Issue 4, 217-237, Physica Verlag, Vienna.

Bacharach, M., 1999. Interactive team reasoning: a contribution to the theory of cooperation, Research in Economics, 53:117-147.

Bacharach M., Gold N. and Sugden S., 2006. Beyond Individual Choice. Teams and Frames in Game Theory, Princeton University Press.

Ben-Ner, A., 1986. Nonprofit Organizations: Why Do They Exist in Market Economies. In: Rose-Ackerman, S. (Ed.). The Economics of Nonprofit Institutions, Columbia University.

Bergstrom, T.C., Goodman, R.P., 1973. Private demands for public goods. The American Economic Review 63 (3), 280-296.

Bergstrom T., Blume L., Varian H., 1986. On The Private Provision of Public Goods. Journal of Public Economics 29, 25-49.

Blecha, B., 1987. The Crowding Parameter and Samuelsonian Publicness. The Journal of Political Economy Vol. 95, No.3, 622-631.

Brewer M. and Gardner W. (1996), "Who is the 'We'? Levels of Collective Identity ans Selfrepresentations", Journal of Personality and Social Psychology, 71(1), 83-93.

Buchanan J., 1965 An Economic theory of Clubs, Economica, New Series, Vol. 32, No125. $1-14$.

Cappellari L., Ghinetti P., Turati G., 2011. On time and Money Donations. The Journal of Socio-Economics 40, 853-867.

Carlin, P., 2001. Evidence of the Volunteer Labor Supply of Married Women. Southern Economic Journal 67 (4), 801-824.

Carpenter J., Matthews P., Ong'ong'a O., 2004. Why Punish? Social reciprocity and the enforcement of prosocial norms, Journal of Evolutionary Economics, Springer, vol. 14(4), 407-429.

Cohen, J., 1977. Source of Peer Group Homogeneity. Sociology of Education Vol. 50, No. 4, 227-241.

Coleman, J., 1988. Social Capital in the Creation of Human Capital, American Journal of Sociology 94, 95-120.

Costa C., Chalip L. Green B. 2006; Reconsidering the Role of Training in Event Volunteers' Satisfaction. Sport Management Review 9: 165182.

Crumpler H., Grossman Ph., 2008. An experimental test of warm glow giving. Journal of Public Economics 92, 1011-1021.

Cuskelly G. , Taylor T. , Hoye R. and Darcy S., 2006. The relationship between volunteer management practices and volunteer retention in community sport organizations, Sport Management Review, Vol. 9, No. 2, 141-63.

Ellingsen T., Johannesson M., Mollestrom J., Munkhammar S., 2012. Social framing effects: Preferences or beliefs? Games and Economic Behavior 76, 117-130.

Evers, A., Riedel, B., 2004. Governing diversity -conceptual and practical challenges illustrated by the example of the German child-care system. Research project TSFEPS "Changing 
Family Structure and Social Policy: Childcare Services as Sources of Social Cohesion” coord. by L. Fraisse and B. Eme.

Farquhar, S.-E., 1993. Constructions of quality in early childhood centres. Thesis submitted for the degree of Doctor of Philosophy, University of Otago, New Zealand.

Fehr E., Schmidt K., 1999. A Theory Of Fairness, Competition, And Cooperation. The Quarterly Journal of Economics, MIT Press Vol. 114(3) 817-868.

Foray, D., Thoron, S., Zimmermann, J-B., 2007. Open Software: Knowledge Openness and Cooperation in Cyberspace. In: Brousseau, E., Curien, N. (Eds.) Internet and Digital Economics, Cambridge: Cambridge University Press.

Glaeser, E.L., Laibson, D.I., Scheinkman, J.A., Soutter, C.L., 2000. Measuring Trust. The Quaterly Journal of Economics Vol. 115, No 3, 811-846.

Gordon, C.W., Babchuk, N., 1959. A Typology of Voluntary Associations American Sociological Review Vol. 24, No.1, 22-29.

Guala F., Mittone L., Ploner M., 2013. Group membership, team preferences, and expectations. Journal of Economic Behavior \& Organization 86, 183-190.

Hansmann, H., 1980. The Role of Nonprofit Enterprise. The Yale Law Journal, Vol. 89, No. $5,835-901$.

Hansmann, H., 1981. Nonprofit Enterprise in the Performing Arts. The Bell Journal of Economics Vol. 12, No. 2, 341-361.

Hansmann, H., 1986. A Theory of Status Organizations, Journal of Law, Economics, \& Organization, Vol. 2, No.1, 119-130.

Hichri, W., Kirman A., 2007. The Emergence of Coordination in Public Good Games. The European Journal of Physics 55, 149-159.

Hoye R., Cuskelly G., Taylor T., Darcy S., 2008. Volunteer motives and Retention in community sport. A study of Australian rugby clubs. Australian Journal of Volunteering, Vol. 13, No 2, 40-48.

Kushman, J., 1979. A Three-Sector Model of Day Care Center Services. The Journal of Human Resources, Vol. 14, No. 4., 543-562.

Laville, J-L., Sainsaulieu, R., 1997. Les fonctionnements associatifs. In: Laville J-L., Sainsaulieu R. (Eds.), Sociologie de l'association, Sociologie économique, Desclée de Brouwer, 271-297.

MacGuire M. 1974. Group Segregation and Optimal Jurisdictions. The Journal of Political Economy, Vol. 82, No 1, 112-132.

McPherson, M., Lovin, L., 1987. Homophily in Voluntary Organizations: Status Distance and the Composition of Face-to-Face Groups. American Sociological Review 52, No. 3, 370-379.

Menchik, P., Weisbrod, B., 1987. Volunteer Labor Supply, Journal of Public Economics. No. 32, 159-183.

Moss, P., 1994. Defining quality: Values, stakeholders and processes. In Moss, P., Pence, A. (Eds.) Valuing quality in early childhood services: New approaches to defining quality, London, 19.

Offerman, T., Sonnemans, J., Schram, A., 1996. Value Orientations, Expectations and Voluntary Contributions in Public Goods. The Economic Journal, 106, No. 437, 817-845.

Okten, C., Weisbrod, B., 2000. Determinants of Donations in Private Nonprofit Markets. Journal of Public Economics 75, 255-272. 
Olson, M., 1971, The Logic of Collective Action: Public Goods and the Theory of Groups, Harvard University Press, Cambridge, Mass.

Popielarz, P., McPherson, M., 1995. On the Edge or in Between: Niche Position, Niche Overlap, and the Duration of Voluntary Association Memberships. The American Journal of Sociology 101, No. 3, 698-720.

Prouteau, L., Wolff, F-C., 2004. Donner son temps: les bénévoles dans la vie associative. Economie et statistique No. 372.

Ray D., Vohra R., 2001. Coalitional Power and Public Goods. The Journal of Political Economy 109, No. 6, 1355-1384.

Ribar, D., Wilhelm, M., 2002. Altruistic and Joy-of-Giving Motivations in Charitable Behavior. Journal of Political Economy 110, No. 2.

Rose A., 1965. The Study of Human Relations, 2nd edition, New York.

Rose-Ackerman, S., 1986. Do Government Grants to Charity Reduce Private Donations? In: Rose-Ackerman, S. (Ed.) The Economics of Nonprofit Institutions, Columbia University.

Rose-Ackerman, S., 1996. Altruism, nonprofits, and economic theory. Journal of Economic Literature. XXXIV: 701-728.

Ross J., 1972. Toward a Reconstruction of Voluntary Association Theory. The British Journal of Sociology 23, No. 1, 20-32.

Salamon, L., Sokolowski, W., List, R., 2003. Global Civil Society: An Overview. The Johns Hopkins Comparative Nonprofit Sector Project, Johns Hopkins University.

Samuelson, P., 1954. The Pure Theory of Public Expenditure. The Review of Economics and Statistics, Vol. 36, No.4, 387-389.

Schervish, P.G., Havens, J.J., 1997. Social participation and charitable giving: a multivariate analysis. Voluntas: International Journal of Voluntary and Nonprofit Organizations 8, No. 3, 235260.

Steinberg, R., 1987. Voluntary Donations and Public Expenditures in a Federalist System. The American Economic Review Vol. 77, No. 1, 24-36.

Sugden, R., 1984 Reciprocity: The Supply of Public Goods Through Voluntary Contributions. The Economic Journal Vol. 94, No. 376, 772-787.

Weisbrod, B., 1977. The Voluntary Nonprofit Sector. An Economic Analysis. University of Wisconsin, Lexington Books.

Weisbrod, B., 1986. Toward a theory of the voluntary nonprofit sector in a three-sector economy. In Rose-Ackerman, S. (Ed.) The Economics of Non Profit Instituitions, Columbia University.

Weisbrod, B., 2000. The non-profit mission an its financing: Growing links between nonprofits and the rest of the economy. In: Weisbrod, B. (Ed.) To profit or not to profit.

Ziemek, S., 2006. Economic Analysis of Volunteers' Motivations-A Cross-Country Study. The Journal of Socio-Economics 35, 532-555. 